\title{
Cytotoxicity of selenium nanoparticles in rat dermal fibroblasts
}

This article was published in the following Dove Press journal:

International Journal of Nanomedicine

20 July 2012

Number of times this article has been viewed

\author{
Joseph F Ramos' \\ Thomas J Webster ${ }^{2}$ \\ 'School of Engineering, Center \\ of Biomedical Engineering, \\ ${ }^{2} \mathrm{School}$ of Engineering and \\ Department of Orthopedics, Brown \\ University, Providence, RI, USA
}

Correspondence: Thomas J Webster School of Engineering and Department of Orthopedics, Brown University,

Providence, RI 02912, USA

Tel 40I-863-23I8

Fax 40I-863-9I07

E-mail thomas_webster@brown.edu
Background: Ventilator-associated pneumonia is a deadly nosocomial infection caused by contaminated endotracheal tubes. It has been shown that polyvinyl chloride (PVC, the endotracheal tube substrate) coated with elemental selenium nanoparticles reduces bacterial adherence and proliferation on PVC by over 99\%. However, it is not known if selenium nanoparticles elicit a cytotoxic effect in vitro. The purpose of this study was to investigate the cytotoxic effects of PVC coated with selenium nanoparticles on fibroblasts, which are mammalian cells central to endotracheal tube intubation.

Methods: Different concentrations of selenium nanoparticles were precipitated onto the PVC surface by reduction of selenium salts using glutathione. Characterization of PVC coated with selenium nanoparticles was done by scanning electron microscopy, energy dispersive x-ray, and contact angle measurements. For the cytotoxicity experiments, fibroblasts were seeded at a density of $5000 \mathrm{~cm}^{2}$ onto PVC coated with three different concentrations of selenium nanoparticles (high, medium, low) and incubated for 4 hours (adhesion) as well as for 24 hours and 72 hours (proliferation). The half-maximal inhibitory concentration $\left(\mathrm{IC}_{50}\right)$ value was determined after 72 hours using an ultrahigh concentration. MTT assays were used to assess cell viability at the indicated time points.

Results: The three concentrations of selenium nanoparticles did not elicit a cytotoxic effect after 72 hours $(P<0.01, \mathrm{n}=3)$. It was found that the $\mathrm{IC}_{50}$ value was at the ultrahigh concentration of selenium nanoparticles. The nanoparticulate elemental selenium concentration previously shown to decrease the function of bacteria was shown not to cause a cytotoxic effect on fibroblasts in vitro.

Conclusion: These findings demonstrate great selectivity between bacteria and healthy cells, and are a viable option for coating endotracheal tubes in order to prevent ventilator-associated pneumonia.

Keywords: selenium, nanoparticle, cytotoxicity, fibroblast, ventilator-associated pneumonia

\section{Introduction}

Medical device-related infection is a growing clinical concern. For example, ventilatorassociated pneumonia is the second most common nosocomial infection in the US. ${ }^{1}$ It is also the deadliest hospital-acquired infection in children and adults, affecting $23 \%$ of all patients receiving mechanical ventilation for more than 24 hours (approximately 250,000 annually). ${ }^{2}$ The Staphylococcus aureus bacterium is responsible for $25 \%$ of all ventilator-associated pneumonia infections and is of great concern to clinicians due to its multidrug resistant strain, ie, methicillin-resistant $S$. aureus (MRSA). ${ }^{3}$ Ventilator-associated pneumonia can also be very costly for both patients 
and hospitals, adding an estimated $\$ 40,000$ dollars to each hospital admission due to the extra intensive care required for treatment. ${ }^{4}$

Inadvertent exposure to bacteria infects up to $54 \%$ of all endotracheal tubes. ${ }^{5}$ These intubated tubes provide a conduit for bacterial access from the extracorporeal environment to the more sterile area of the lungs. Through cell division and biochemical recruitment of extracellular DNA, proteins, and exopolysaccharides, these adherent bacteria form an aggregate of microorganisms called a biofilm. Ventilation through these infected endotracheal tubes, or even condensation of humidified air, breaks off pieces of the biofilm, causing gross and micro aspiration of bacteria into the distal bronchi, followed by bacterial proliferation and parenchymal invasion. ${ }^{6-8}$ Endotracheal tube intubation also thwarts the cough reflex and compromises mucociliary clearance, making it nearly impossible to expel contaminated secretions. ${ }^{9,10}$ The current techniques for preventing ventilator-associated pneumonia, ie, sterilization of equipment, better hospital practices, systemic antibiotic administration, and re-engineering of the endotracheal tube, have not proven to be efficacious.

As a result, the most promising and straightforward strategy for decreasing ventilator-associated pneumonia is to fabricate endotracheal tubes with antibacterial agents that resist bacterial attachment. However, currently used materials, such as silver and silver compounds, eg, silver sulfadiazine, have been shown to be ineffective at preventing bacterial attachment in the long term. ${ }^{1-13}$ Moreover, the use of these silver-coated endotracheal tubes is contraindicated for persons who are allergic to silver; ${ }^{14}$ silver is also not naturally found in the body. In contrast, selenium is an essential trace element found in the human body. Adults require $55-70 \mu \mathrm{g}$ of selenium per day, with an upper tolerable limit of $400 \mu \mathrm{g}$, to make selenoproteins, which play a vital role in the human antioxidant defense system, redox control of cell reactions, and thyroid hormone metabolism. Elemental selenium also naturally possesses antibacterial properties. Studies of these antibacterial properties have demonstrated that elemental selenium-enriched probiotics ${ }^{15}$ and organoselenium compounds ${ }^{16,17}$ have antibacterial effects in vitro and in vivo against Escherichia coli and S. aureus, respectively. Furthermore, studies have demonstrated that selenium nanoparticles reduce $S$. aureus adhesion and proliferation on commercial endotracheal tubes by over $99 \%{ }^{18}$ Overall, the bactericidal action of selenium is due to its ability to catalyze the oxidation of intracellular thiols, causing death of bacteria. ${ }^{18-20}$
Symptoms of selenium toxicity (called selenosis) include gastrointestinal disorders, alopecia, fatigue, and irritability. ${ }^{21}$ The chronic dose of selenium that results in extreme cases of toxicity is very high, at approximately $2400 \mu \mathrm{g} / \mathrm{day} .{ }^{21}$ Studies on the toxicity of elemental selenium have been promising in demonstrating that its use will be benign. ${ }^{22}$ Regarding toxicity of selenium nanoparticles, studies have shown that selenium nanoparticles have an efficacy comparable with that of selenium compounds as an antioxidant, but have a greatly reduced risk of toxicity. ${ }^{23,24}$ However, studies investigating the toxicity of selenium have focused on systemic toxicity in vivo and have not focused on in vitro toxicity to mammalian cells central to endotracheal tube intubation, such as fibroblasts. Thus, the objective of this study was to ascertain the cytotoxic effect of selenium nanoparticles on fibroblasts in vitro.

\section{Materials and methods Synthesis of selenium nanoparticles}

PVC samples $(6 \mathrm{~mm} \times 3 \mathrm{~mm} \times 1 \mathrm{~mm})$ were cut from commercial endotracheal tubes (Hudson RCI, Research Triangle Park, NC) using a Fiskars rectangular hole punch (Fiskars Corporation, Helsinki, Finland). The PVC samples were then rinsed in increasing concentrations of ethanol $(30 \%, 50 \%$, $70 \%$, and $100 \%$ ) for 10 minutes each and then air-dried in a sterile laminar flow hood for 12 hours. The cleaned and sterilized PVC were used as controls and base substrates for the colloidal precipitation with four different concentrations of selenium nanoparticles, ie, $46.5 \mu \mathrm{g} / \mathrm{mL}$ (ultrahigh), $31 \mu \mathrm{g} / \mathrm{mL}$ (high), $15.5 \mu \mathrm{g} / \mathrm{mL}$ (medium), and $7.8 \mu \mathrm{g} / \mathrm{mL}$ (low). For the ultrahigh concentration, $6.25 \mathrm{~mL}$ of deionized water $\left(\mathrm{DIH}_{2} \mathrm{O}\right)$ and $6.25 \mathrm{~mL}$ of $100 \mathrm{mM}$ glutathione (reduced form, Alfa Aesar, Ward Hill, MA) were added to a $50 \mathrm{~mL}$ conical tube containing the PVC samples, followed by $17.5 \mathrm{~mL}$ of $25 \mathrm{mM}$ sodium selenite $\left(\mathrm{Na}_{2} \mathrm{SeO}_{3}, \mathrm{Alfa}\right.$ Aesar). After gentle mixing, $2 \mathrm{~mL}$ of $1 \mathrm{M}$ sodium hydroxide (Alfa Aesar) was added to bring the $\mathrm{pH}$ of the mixture into the alkaline range. The same reagents and methodology were used for the high, medium, and low concentrations, albeit the reagent amounts changed. For the high concentration, $7.5 \mathrm{~mL}$ of $\mathrm{DIH}_{2} \mathrm{O}, 7.5 \mathrm{~mL}$ of glutathione, $15 \mathrm{~mL}$ of $\mathrm{Na}_{2} \mathrm{SeO}_{3}$, and $2 \mathrm{~mL}$ of sodium hydroxide were used. For the medium concentration, $10 \mathrm{~mL}$ of $\mathrm{DIH}_{2} \mathrm{O}, 10 \mathrm{~mL}$ of glutathione, $10 \mathrm{~mL}$ of $\mathrm{Na}_{2} \mathrm{SeO}_{3}$, and $2 \mathrm{~mL}$ of sodium hydroxide were

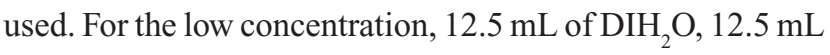
of glutathione, $5 \mathrm{~mL}$ of $\mathrm{Na}_{2} \mathrm{SeO}_{3}$, and $2 \mathrm{~mL}$ of sodium hydroxide were used (Table 1 ). In all reactions, the reduction of sodium selenite by glutathione immediately formed 
Table I Final concentration of selenium in the colloidal synthesis solution

\begin{tabular}{|c|c|c|c|c|}
\hline \multirow[t]{2}{*}{ Reagents used } & \multicolumn{4}{|c|}{ Amount of reagents used } \\
\hline & $\begin{array}{l}{[\mathrm{Se}]=46.5 \mu \mathrm{g} / \mathrm{mL}} \\
\text { ("ultra-high") }\end{array}$ & $\begin{array}{l}{[\mathrm{Se}]=3 \mathrm{I} \mu \mathrm{g} / \mathrm{mL}} \\
\text { ("high") }\end{array}$ & $\begin{array}{l}{[\mathrm{Se}]=15.5 \mu \mathrm{g} / \mathrm{mL}} \\
\text { ("medium") }\end{array}$ & $\begin{array}{l}{[\mathrm{Se}]=7.8 \mu \mathrm{g} / \mathrm{mL}} \\
\text { ("low") }\end{array}$ \\
\hline Deionized water $\left(\mathrm{DIH}_{2} \mathrm{O}\right)$ & $6.25 \mathrm{~mL}$ & $7.5 \mathrm{~mL}$ & $10 \mathrm{~mL}$ & $12.5 \mathrm{~mL}$ \\
\hline Glutathione (GSH), $100 \mathrm{mM}$ & $6.25 \mathrm{~mL}$ & $7.5 \mathrm{~mL}$ & $10 \mathrm{~mL}$ & $12.5 \mathrm{~mL}$ \\
\hline Sodium selenite $\left(\mathrm{Na}_{2} \mathrm{SeO}_{3}\right), 25 \mathrm{mM}$ & $17.5 \mathrm{~mL}$ & $15 \mathrm{~mL}$ & $10 \mathrm{~mL}$ & $5 \mathrm{~mL}$ \\
\hline Sodium hydroxide $(\mathrm{NaOH})$, I $\mathrm{N}$ & $2 \mathrm{~mL}$ & $2 \mathrm{~mL}$ & $2 \mathrm{~mL}$ & $2 \mathrm{~mL}$ \\
\hline
\end{tabular}

selenium nanoparticles, which were precipitated onto the PVC samples as visualized by a color change of the reactant solution from clear to milky red. ${ }^{18}$ For each concentration, the conical tubes were left untouched for 30 minutes to allow the selenium nanoparticles to precipitate onto the PVC samples both intraluminally and extraluminally. The substrates were then removed and rinsed in $10 \mathrm{~mL}$ of $\mathrm{DIH}_{2} \mathrm{O}$ for 24 hours. The uncoated (control) and selenium nanoparticle-coated substrates were immersed in $70 \%$ ethanol for 30 minutes. The ethanol was then removed and the substrates were sterilized in a laminar flow hood under ultraviolet light for 24 hours.

\section{Characterization of selenium nanoparticles}

For material surface characterization studies, the PVC samples were sputter-coated with a thin layer (approximately $90 \AA$ ) of gold and observed under scanning electron microscopy (LEO 1530VP FE-4800) at $5 \mathrm{kV}$. For chemical characterization, energy dispersive $\mathrm{x}$-ray spectroscopy with an acceleration voltage of $20 \mathrm{kV}$ was employed. Contact angle measurements of uncoated and selenium nanoparticle-coated PVC were also conducted. Contact angles easily and quickly identified the hydrophobicity/hydrophilicity of a proposed material for medical applications, which is of paramount importance for the interaction between the substrate and biological entities in the body. To measure the hydrophobicity/hydrophilicity of uncoated and selenium nanoparticle-coated PVC, a drop shape analysis system (DSA-10, Kruss, Hamburg, Germany) with analysis software (DSA 1 v 1.80) was used. A $2 \mu \mathrm{L}$ drop of water was placed onto the substrates, and contact angles were recorded within 10 seconds at room temperature. All characterization measurements were repeated nine times for each sample.

\section{In vitro assays for cytotoxicity experiments}

To investigate cytotoxicity via cell adhesion and proliferation of PVC coated with selenium nanoparticles, a cell line of rat dermal fibroblasts was obtained from the American Type Culture Collection (CRL-1213, Manassas, VA).
The fibroblasts were grown in Eagle's Minimum Essential Medium (ATCC) supplemented with 10\% fetal bovine serum (Hyclone, Rockford, IL), and 1\% penicillin-streptomycin (Hyclone) in a standard cell culture incubator $\left(37^{\circ} \mathrm{C}\right.$, humidified, $5 \% \mathrm{CO}_{2}, 20 \% \mathrm{O}_{2}$ environment, nonshaking). Every 24 hours the old medium was removed, the cells were cleaned three times with phosphate-buffered saline, and new medium was added. After confluence was reached (approximately 72 hours), the cells were seeded at a density of approximately 5000 cells $/ \mathrm{cm}^{2}$ in sterile 24 -well plates that contained a PVC sample coated with the high, medium, or low concentration of selenium nanoparticles; uncoated PVC samples were used as controls. The samples were incubated in a standard cell culture incubator for 4 hours for the cell adhesion assay and 24 and 72 hours for the proliferation assays. The reduction of tetrazolium salts in a colorimetric MTT assay is now widely accepted as a reliable method for examining cell adhesion and proliferation..$^{25,26}$ For the MTT assay, a CellTiter 96 nonradioactive assay (ATCC) was used and the absorbance, which corresponded to total cell number, was recorded using a microplate spectrophotometer $(570 \mathrm{~nm}$, SpectraMax, Molecular Devices, Sunnyvale, CA). To ascertain the $\mathrm{IC}_{50}$ value, the ultrahigh concentration of selenium nanoparticles was used. The $\mathrm{IC}_{50}$ value is a quantitative measurement that indicates the concentration of selenium nanoparticles needed to inhibit a biological process (ie, fibroblast viability) by half. The samples were incubated in a standard cell culture incubator for 72 hours and then a MTT assay was used to determine cell viability.

All experiments were conducted in triplicate and repeated three times. Data were collected, and significant differences were assessed using the probability associated with one-tailed Student's $t$-tests.

\section{Results \\ Synthesis of selenium nanoparticles}

Visual characterization by scanning electron microscopy of the coating density of PVC coated and not coated 
with selenium nanoparticles can be seen in Figure 1. The morphology in the high-magnification tilted scanning electron microscopic image (Figure 2) strongly suggests that the selenium nanoparticles were bonded (by physicochemical forces, not covalently) to the substrate. In fact, previous studies have tried to remove the adherent selenium nanoparticles using sonication, but could not. ${ }^{18}$ The surface coverage of selenium nanoparticles for the medium concentration (determined from scanning electron microscopic images using an image processing program, ie, ImageJ, National Institutes of Health, Bethesda, MD) was approximately $10 \%$, or about $300 \mu \mathrm{g}$. X-ray spectra were used to confirm the chemistry of the selenium nanoparticles. Selenium peaks were observed in the area coated with selenium nanoparticles, which confirmed that the nanoparticles were in fact elemental selenium (Figure 3). Contact angle measurements demonstrated that selenium nanoparticles reduced the contact angles, or made the PVC more hydrophilic (Figure 4).

\section{Cytotoxicity studies}

The viability of fibroblasts as determined by MTT assays after the 4-hour (adhesion) time point showed that the number of live cells on PVC coated with selenium nanoparticles was significantly higher than the number of live cells on PVC not coated with selenium nanoparticles. The number of live cells also increased as the final concentration of selenium in the colloidal synthesis solution increased. Furthermore, the viability of fibroblasts as determined by MTT assays after the 24-hour and 72-hour (proliferation) time points was significantly higher on PVC coated with selenium nanoparticles as compared with the PVC not coated with selenium nanoparticles. The number of cells proliferating on the PVC coated with selenium nanoparticles between the 24-hour and 72-hour time points neither significantly increased nor decreased.

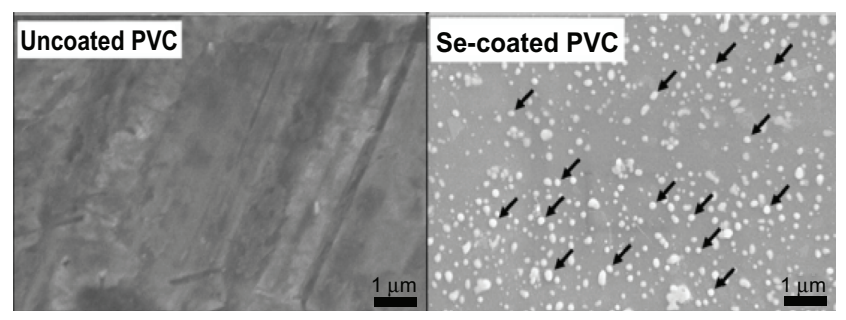

Figure I Scanning electron microscopic images of PVC coated with selenium nanoparticles (right panel) and not coated with selenium nanoparticles (left panel). Arrows indicate selenium nanoparticles (nonexhaustive). The selenium nanoparticles had sizes ranging from approximately $80 \mathrm{~nm}$ to $200 \mathrm{~nm}$ and are uniformly coated on the substrates. Selenium nanoparticle coverage is approximately $10 \%$, or $300 \mu g^{18}$ Previously published studies demonstrate the surface coverage for all samples of interest in this study, and are given in Table.$^{18}$

Abbreviation: PVC, polyvinyl chloride.

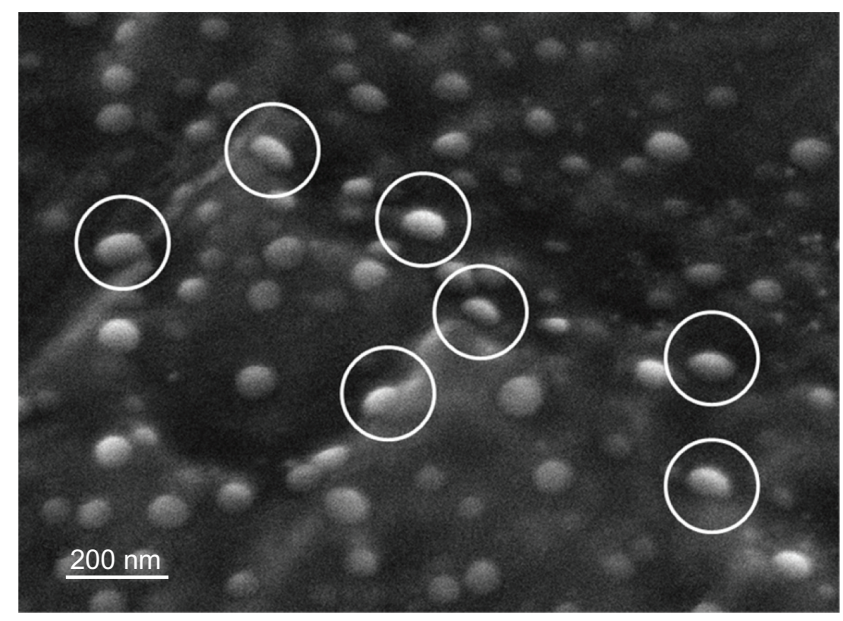

Figure 2 Scanning electron microscopic image, taken at a $45^{\circ}$ tilt, of the medium concentration selenium nanoparticles precipitated on polyvinyl chloride. Note: The hemispherical shape of the selenium nanoparticles on the substrate surface.

The number of live cells adhering and proliferating on PVC not coated with selenium nanoparticles from 4 hours to 72 hours also did not significantly increase (Figure 5). Results from the $\mathrm{IC}_{50}$ studies revealed that the concentration of selenium nanoparticles coated on PVC needed to inhibit fibroblast viability by half was approximately $46.5 \mu \mathrm{g} / \mathrm{mL}$. This is because $52 \%$ of the fibroblasts died when exposed to this ultrahigh concentration of selenium nanoparticles, or $2 \%$ more than the concentration needed to ascertain the $\mathrm{IC}_{50}$ value (Figure 6).

\section{Discussion}

Visual characterization by scanning electron microscopy showed that the coating density of PVC coated with selenium nanoparticles as compared with PVC not coated with selenium nanoparticles. The morphology in the high-magnification tilted scanning electron microscopic image strongly suggest that the selenium nanoparticles were bonded to the substrate. Coupled with the fact that cleaning of the PVC samples before coating with the selenium nanoparticles was found to be crucial for the deposition of selenium nanoparticles on the substrate surface, it is speculated that the selenium nanoparticles were formed through a nucleation process. The nucleation sites on the PVC surfaces, eg, defects and impurities, may have also served as high-energy regions for the selenium nucleation process to occur. Determination of the surface coverage of selenium nanoparticles by scanning electron microscopy for all concentrations was approximately $10 \%$ (about $300 \mu \mathrm{g}$ per endotracheal tube), or approximately $100 \mu \mathrm{g}$ less than the upper tolerable limit. Energy-dispersive x-ray spectra were used to confirm the chemistry of the selenium nanoparticles. 

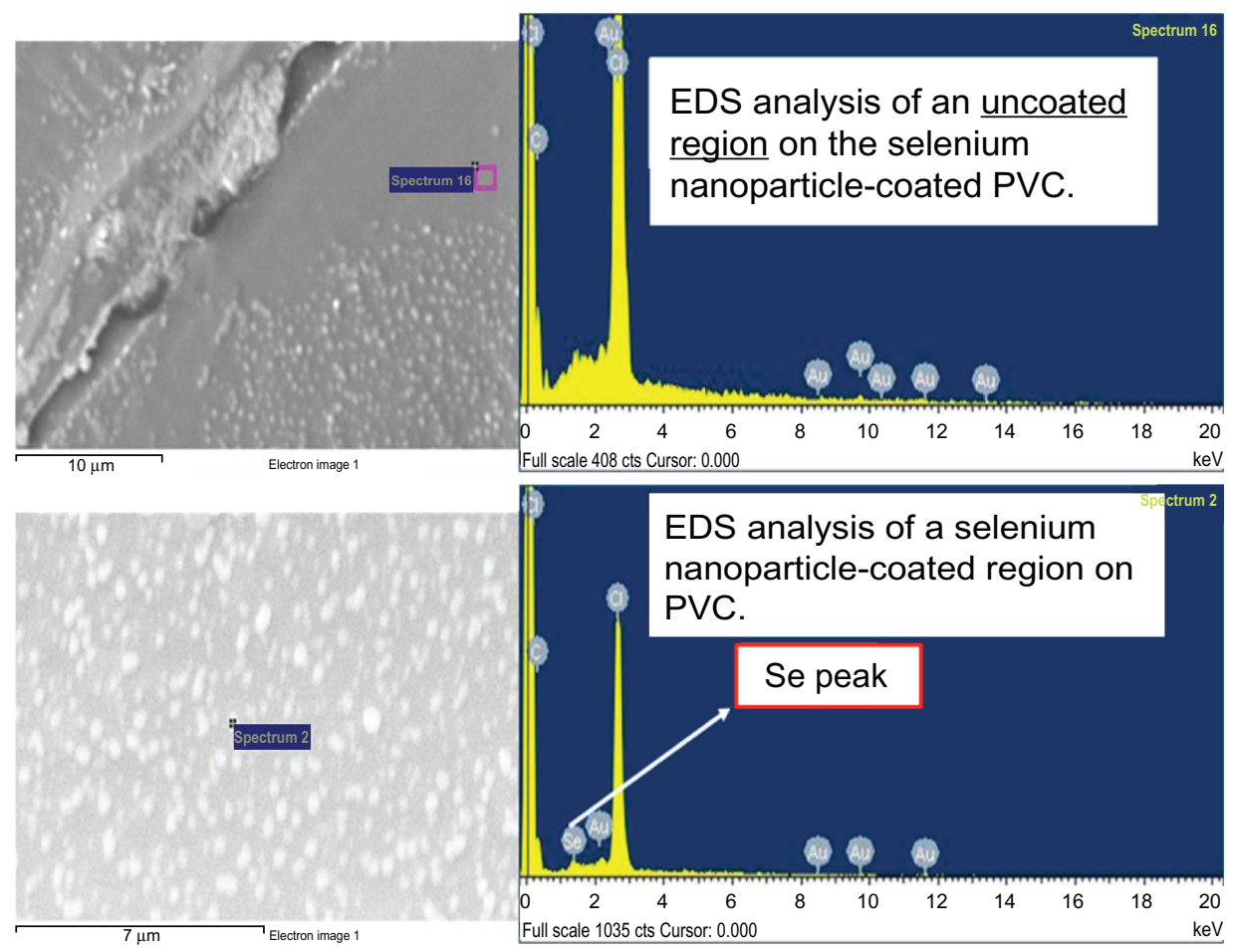

Figure 3 X-ray spectra of an uncoated region on PVC (top) and a region on PVC coated with selenium nanoparticles (bottom). Elemental selenium peaks are detected in PVC coated with selenium nanoparticles, demonstrating that the nanoparticles were in fact selenium. Peaks of carbon (C) and chlorine (Cl) present are from the PVC substrate; peaks of gold $(\mathrm{Au})$ present are from the sputter-coating process.

Abbreviations: PVC, polyvinyl chloride; EDS, energy dispersive spectrum.

Selenium peaks were observed in the area coated with selenium nanoparticles, which confirmed that the nanoparticles were in fact elemental selenium. Contact angle measurements demonstrate the hydrophobicity/hydrophilicity of a medical implant, which is of the utmost importance for potential use in the human body. If the implanted material is water-repelling (ie, hydrophobic), a water drop on the surface of a material will have a contact angle greater than $90^{\circ}$. Otherwise, if the material is water-attracting (ie, hydrophilic), the contact angle will be less than $90^{\circ}$. Contact angle measurements

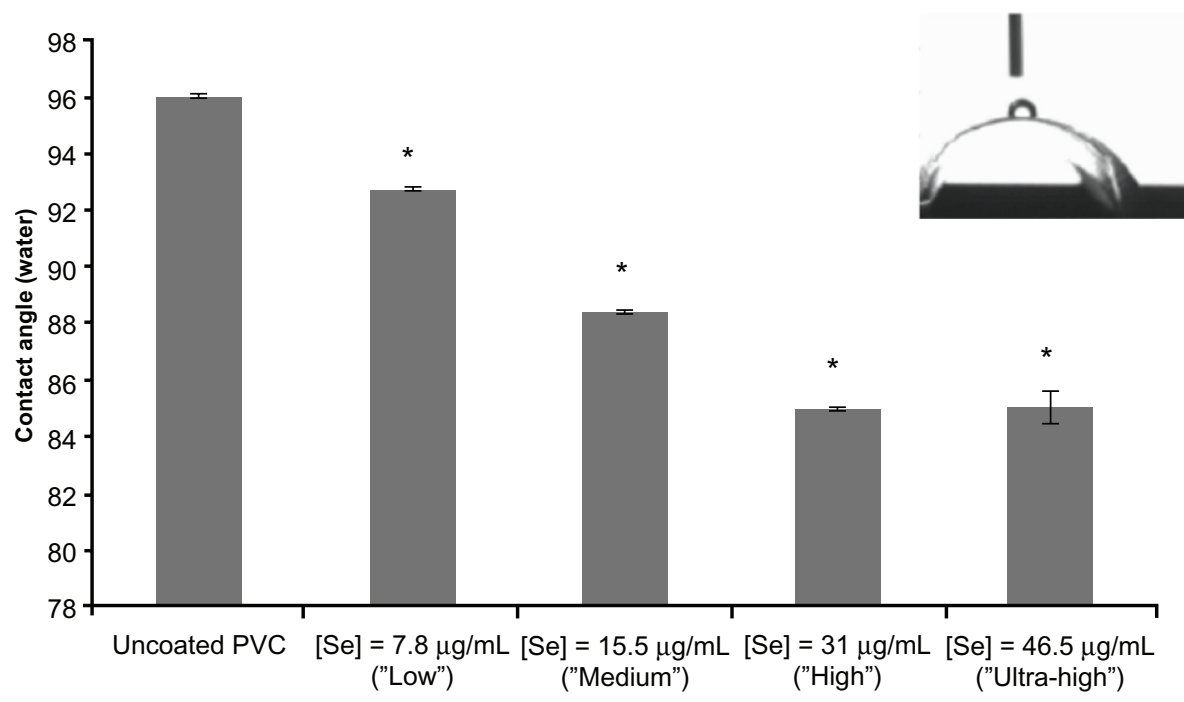

Final concentration of selenium in the colloidal synthesis solution

Figure 4 Water contact angles of PVC coated and not coated with selenium nanoparticles.

Notes: ${ }^{*} P<0.01$ compared with uncoated PVC. The data are presented as the mean \pm standard error of the mean $(n=3)$.

Abbreviation: PVC, polyvinyl chloride. 


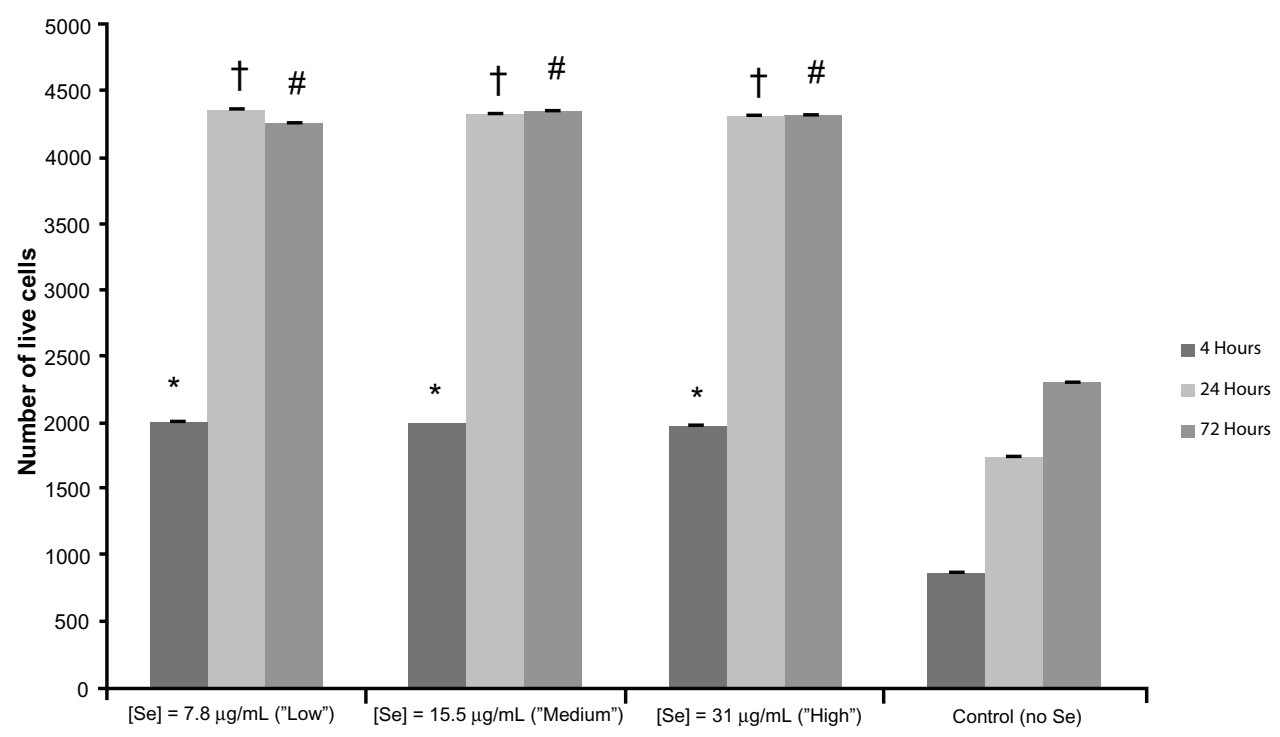

Final concentration of selenium in the colloidal synthesis solution

Figure 5 Increased fibroblast viability upon exposure to PVC coated with selenium nanoparticles.

Notes: $* P<0.05$ for all concentrations at the 4-hour (adhesion) time point as compared with the control; ${ }^{\dagger} P<0.01$ for all concentrations at the 24 -hour (proliferation) time point as compared with the control; ${ }^{\#} P<0.01$ for all concentrations at the 72 -hour (proliferation) time point as compared with the control. The data are presented as the mean \pm standard error of the mean $(n=3)$.

Abbreviation: PVC, polyvinyl chloride.

demonstrated that selenium nanoparticles reduced the contact angles, or made the PVC more hydrophilic. This is significant because not only is wettability crucial for ultimate use in a human subject, but hydrophilic surfaces have also been shown to decrease free-swimming bacteria adherence as compared with hydrophobic surfaces. ${ }^{27}$

The viability of fibroblasts as determined by MTT assays after the 4-hour (adhesion) time point indicates that the number of live cells on PVC coated with selenium nanoparticles was significantly higher than the number of live cells on PVC not coated with selenium nanoparticles. Furthermore, the number of live cells also increased as the final concentration of selenium in the colloidal synthesis solution increased. The viability of fibroblasts as determined by MTT assays after the 24-hour and 72-hour (proliferation) time points was also significantly higher on the PVC coated

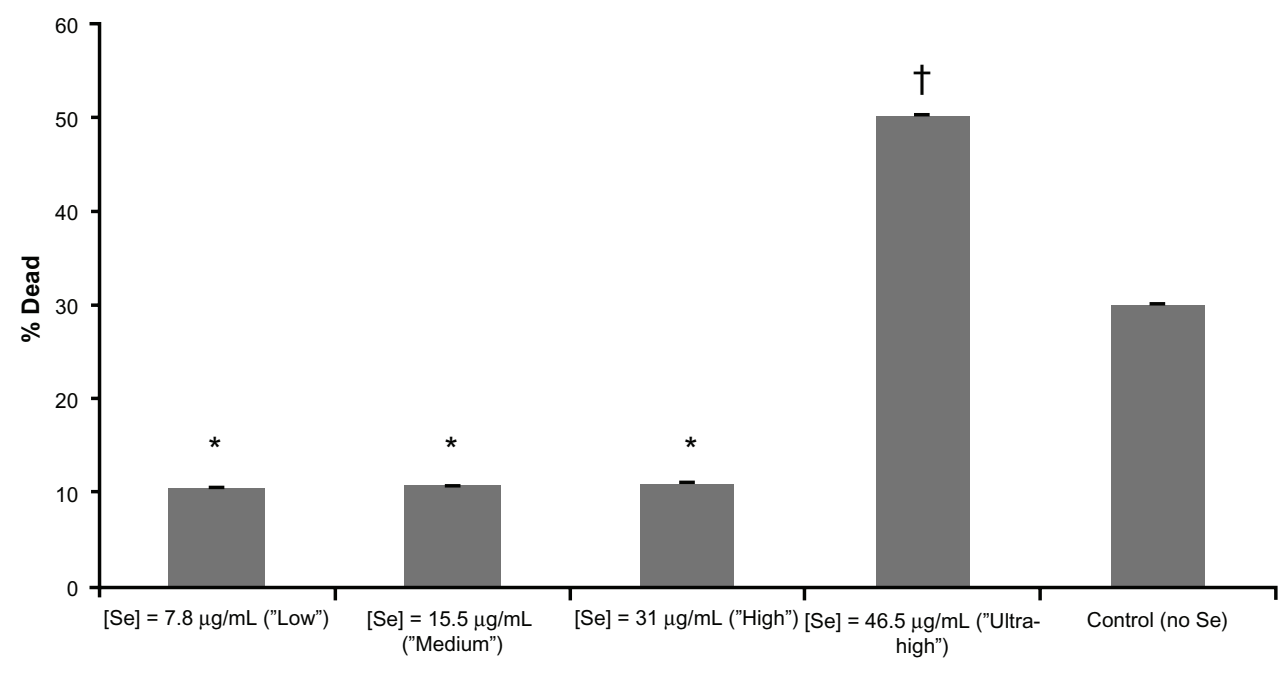

Final concentration of selenium in the colloidal synthesis solution

Figure 6 Half maximal inhibitory concentration $\left(\mathrm{IC}_{50}\right)$ studies show a decrease in fibroblast viability after 72 hours when exposed to the ultrahigh concentration of selenium nanoparticles.

Notes: $* P<0.05$ for the high, medium, and low concentrations as compared with the control; ${ }^{\dagger} P<0.0 \mathrm{I}$ for all concentrations at the ultra-high concentration as compared with the control. The data are presented as the mean \pm standard error of the mean $(n=3)$. 
with selenium nanoparticles as compared with the PVC not coated with selenium nanoparticles. This indicates that fibroblasts may preferentially grow on PVC coated with selenium nanoparticles, indicating that elemental selenium may have a protective, healthy effect on mammalian cells. Results from the $\mathrm{IC}_{50}$ studies revealed that the concentration of selenium nanoparticles coated onto PVC needed to inhibit fibroblast viability by half was approximately $46.5 \mu \mathrm{g} / \mathrm{mL}$, because $52 \%$ of the fibroblasts died when exposed to this ultrahigh concentration of selenium nanoparticles, which is $2 \%$ more than the concentration needed to ascertain the $\mathrm{IC}_{50}$ value.

\section{Conclusion}

This work demonstrates the potential of using selenium nanoparticles as a nontoxic, antibacterial agent for PVC-related medical devices, particularly endotracheal tubes. Specifically, it has been shown using techniques such as scanning electron microscopy, energy dispersive x-ray spectroscopy, and contact angle measurements, that four different concentrations of elemental selenium nanoparticles can be successfully coated onto samples cut from commercial PVC endotracheal tubes. These aforementioned techniques revealed two critical findings. First, the surface coverage of selenium nanoparticles was found to be approximately $300 \mu \mathrm{g}$. This is critical for the ultimate use in an intubated patient because, even if all of the selenium nanoparticles were to elute from the coated endotracheal tube at once, it would not reach the suggested upper tolerable intake level of $400 \mu \mathrm{g} /$ day. Second, contact angle measurements revealed that coating PVC with selenium nanoparticles made the PVC more hydrophilic. This is significant because hydrophilicity is of the utmost importance for ultimate use in a human subject.

The cytotoxicity of selenium nanoparticles in terms of fibroblast viability was assessed and it has been determined that no cytotoxic effect was elicited after 72 hours. Results from the $\mathrm{IC}_{50}$ studies revealed that a concentration of selenium 1.5 times greater than the high concentration inhibited fibroblast viability by half. Despite the potential cytotoxicity of selenium nanoparticles, these results are significant, as the concentration of selenium nanoparticles to be used to coat an endotracheal tube for antibacterial purposes could likely be the low or medium concentration, given that both have been shown to reduce $S$. aureus adhesion and proliferation by over $99 \% .{ }^{18}$ Thus, by using one of these concentrations, the toxic level of selenium would never be reached.

For the first time, to the authors' knowledge, nanoparticulate elemental selenium has been shown not to have a cytotoxic effect on mammalian cells in vitro, ie, fibroblasts, central to endotracheal tube intubation. These results suggest that selenium nanoparticles have great selectivity for discriminating between bacteria and healthy cells, and display a viable option for coating endotracheal tubes in order to prevent ventilator-associated pneumonia, or any other medical device made of PVC that instigates a hospital-acquired infection.

\section{Acknowledgment}

The authors would like to thank the Hermann Foundation for providing the funding for this research.

\section{Disclosure}

The authors report no conflicts of interest in this work.

\section{References}

1. Chastre J, Fagon JY. Ventilator-associated pneumonia. Am J Respir Crit Care Med. 2002;165:867-903.

2. Seckel M. Implementing evidence-based practice guidelines to minimize ventilator-associated pneumonia. Available from: http://www.aacn.org/ WD/CETests/Media/AN0107CE.pdf. Accessed January 7, 2011.

3. Centers for Disease Control and Prevention. Device-associated events: VAP. 2011. Available from: http://www.cdc.gov/nhsn/PDFs/ pscManual/6pscVAPcurrent.pdf. Accessed August 20, 2011.

4. Office of Quality and Performance. FY 2008, Q1 technical manual for the VHA performance measurement system. 2007. http://www. shepherd.org/files/wysiwyg/file/2011\%20final $\% 20$ figures $\% 20$ for $\% 20$ media\%20-\%20device\%20infections.pdf.

5. Donlan RM. Biofilms and device-associated infections. Emerg Infect Dis. 2001;7:277-281.

6. Estes RJ, Meduri GU. The pathogenesis of ventilator-associated pneumonia: I. Mechanisms of bacterial transcolonization and airway inoculation. Intensive Care Med. 1995;21:365-383.

7. Safdar N, Crnich CJ, Maki DG. The pathogenesis of ventilator-associated pneumonia: its relevance to developing effective strategies for prevention. Respir Care. 2005;50:725-739.

8. Alcon A, Fàbregas N, Torres A. Hospital-acquired pneumonia: etiologic considerations. Infect Dis Clin North Am. 2003;17:679-695.

9. Bone DK, Davis JL, Zuidema GD, Cameron JL. Aspiration pneumonia: prevention of aspiration in patients with tracheostomies. Ann Thorac Surg. 1974;18:30-37.

10. Gal TJ. Effects of endotracheal intubation on normal cough performance. Anesthesiology. 1980;52:324-329.

11. Yahav D, Rozen-Zvi B, Gafter-Gvili A, Leibovici L, Gafter U, Paul M. Antimicrobial lock solutions for the prevention of infections associated with intravascular catheters in patients undergoing hemodialysis: systematic review and meta-analysis of randomized, controlled trials. Clin Infect Dis. 2008;47:83-93.

12. Trerotola SO, Johnson MS, Shah H, et al. Tunneled hemodialysis catheters: use of a silver-coated catheter for prevention of infection: a randomized study. Radiology. 1998;207:491-496.

13. Logghe C, Van Ossel C, D’Hoore W, Ezzedine H, Wauters G, Haxhe JJ. Evaluation of chlorohexidine and silver-sulfadiazine impregnated central venous catheters for the prevention of bloodstream infection in leukaemic patients: a randomized controlled trial. J Hosp Infect. 1997;37: $145-156$.

14. Lansdown AB. Silver in health care: antimicrobial effects and safety in use. Curr Probl Dermatol. 2006;33:17-34.

15. Yang J, Huang K, Qin S, Wu X, Zhao Z, Chen F. Antibacterial action of selenium-enriched probiotics against pathogenic Escherichia coli. Dig Dis Sci. 2009;54:246-254. 
16. Ratushnaya EV, Kirova YI, Suchkov MA, Drevko BI, Borodulin VB. Synthesis and antibacterial activity of organoselenium compounds. Pharm Chem J. 2002;36:652-653. http://www.springerlink.com/ content/1784168r2t302436/.

17. Pietka-Ottlik M, Wójtowicz-Młochowska H, Kołodziejczyk K, Piasecki E, Młochowski J. New organoselenium compounds active against pathogenic bacteria, fungi and viruses. Chem Pharm Bull. 2008;56:1423-1427.

18. Ramos JF. Selenium nanoparticles for the prevention of polyvinyl chloride-related medical infections. Master's thesis. Providence, RI: Brown University School of Engineering; 2012.

19. Spallholz JE. On the nature of selenium toxicity and carcinostatic activity. Free Radic Biol Med. 1994;17:45-64.

20. Sieber F, Günther WHH, Daziano J-P, Krieg-Kowald M, Bousbaa J, Bula RJ, inventors. Method of making, and the use of cytotoxic agents containing elemental selenium. United States patent US 7205002. April 17, 2007.

21. Navarro-Alarcon M, Cabrera-Vique C. Selenium in food and the human body: a review. Sci Total Environ. 2008;400:115-141.
22. Rayman MP. The importance of selenium to human health. Lancet. 2000;356:233-241.

23. Wang $\mathrm{H}$, Zhang J, Yu H. Elemental selenium at nano size possesses lower toxicity without compromising the fundamental effect on selenoenzymes: comparison with selenomethionine in mice. Free Radic Biol Med. 2007;42:1524-1533.

24. Peng D, Zhang J, Liu Q, Taylor EW. Size effect of elemental selenium nanoparticles (Nano-Se) at supranutritional levels on selenium accumulation and glutathione S-transferase activity. J Inorg Biochem. 2007;101:1457-1463.

25. Bakand S, Winder C, Hayes A. Comparative in vitro cytotoxicity assessment of selected gaseous compounds in human alveolar epithelial cells. Toxicol In Vitro. 2007;21:1341-1347.

26. Bakand S, Hayes A, Dechsakulthorn F. Nanoparticles: a review of particle toxicology following inhalation exposure. Inhal Toxicol. 2012;24:125-135

27. Balazs DJ, Triandafillu K, Wood $\mathrm{P}$, et al. Inhibition of bacterial adhesion on PVC endotracheal tubes by RF-oxygen glow discharge, sodium hydroxide and silver nitrate treatments. Biomaterials. 2004;25:2139-2151.
International Journal of Nanomedicine

\section{Publish your work in this journal}

The International Journal of Nanomedicine is an international, peerreviewed journal focusing on the application of nanotechnology in diagnostics, therapeutics, and drug delivery systems throughout the biomedical field. This journal is indexed on PubMed Central, MedLine, CAS, SciSearch $\AA$, Current Contents ${ }^{\circledR} /$ Clinical Medicine,

\section{Dovepress}

Journal Citation Reports/Science Edition, EMBase, Scopus and the Elsevier Bibliographic databases. The manuscript management system is completely online and includes a very quick and fair peer-review system, which is all easy to use. Visit http://www.dovepress.com/ testimonials.php to read real quotes from published authors. 